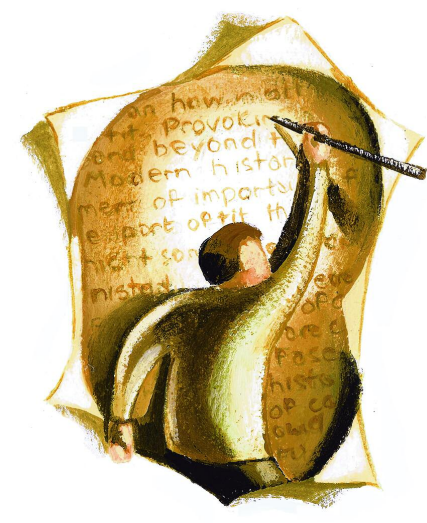

\section{Treponema pallidum}

\section{macrolide resistance in $\mathrm{BC}$}

Since mid-I997 British Columbia has experienced an outbreak of syphilis, initially in heterosexuals and more recently among men who have sex with men (MSM). Starting in 1999, primarily in patients presenting to the sexually transmitted diseases clinic at the $\mathrm{BC}$ Centre for Disease Control (BCCDC), moist lesions of primary and secondary syphilis were swabbed for polymerase chain reaction (PCR) testing for Treponema pallidum. The PCR method used was polA gene amplification using a CDC protocol. ${ }^{1}$

When the question of azithromycin resistance arose in 2004, specimens were examined retrospectively for the mutation in the T. pallidum 23 sRNA gene in collaboration with investigators from the University of Washington. ${ }^{2}$

From 2000-2003, I of 47 positive PCRs showed resistance in a travelacquired heterosexual case. In 2004, 4 of 9 positive PCRs showed the resistant gene, all in MSM.

The 23sRNA gene correlated with clinical resistance to azithromycin in Dublin and San Francisco. ${ }^{2}$

All of the BC patients received penicillin $\mathrm{G}$ benzathine or doxycycline; therefore, treatment failure with azithromycin was not tested.

Treatment of choice in BC for early syphilis is one dose of penicillin $G$ benzathine (2.4 MU intramuscularly). Oral doxycycline therapy (1oo mg twice daily for 2 weeks) is a second-line treatment, with oral azithromycin ther- apy (one 2-g dose) as a third-line treatment, especially in noncompliant patients who refuse injections. This sequence is in compliance with the Canadian and US STD treatment guidelines. ${ }^{3,4}$

In a recent study in Africa, a 2-g oral dose of azithromycin was as effective as a 2.4-MU intramuscular dose of penicillin $\mathrm{G}$ benzathine. ${ }^{5}$ However, in developed countries, because of resistance trends, azithromycin should be reserved as a third-line treatment for early syphilis, and patients thus treated should be followed closely, both serologically and clinically.

\section{Muhammad G. Morshed}

\section{Hugh D. Jones}

BC Centre for Disease Control

University of British Columbia Centre

for Disease Control

Department of Pathology and

Laboratory Medicine

University of British Columbia

Vancouver, BC

\section{REFERENCES}

I. Hsi L, Rodes B, Chen CY, et al. New tests for syphilis: rational design of a PCR method for detection of Treponema pallidum in clinical specimens using unique regions of the DNA polymerase I gene. JClin Microbiol 200I;39:194I-6.

2. Lukehart SA, Godornes C, Molini MS, et al. Macrolide resistance in Treponema pallidum in the United States and Ireland. N Engl J Med 2004;35I: I54-8

3. Health Canada. Canadian STD Guidelines. I998.

4. US Centers for Disease Control and Prevention. Sexually transmitted diseases treatment guidelines 2002. MMWR Recomm Rep 2002;5I(RR-6):I-78.

5. Riedner G, Rusizoka M, Todd J, et al. Single-dose azithromycin versus penicillin $\mathrm{G}$ benzathine for the treatment of early syphilis. $N$ Engl J Med 2005; 353:1236-44.

Competing interests: None declared.

DOI:I0.1503/cmaj.1050256

\section{Determining optimal}

\section{catheterization rates}

In an article by Michelle Graham and colleagues, ${ }^{1}$ an attempt was made to determine optimal catheterization rates by detecting the population rate of cardiac catheterization beyond which the yield of high-risk coronary artery disease does not rise. However, some issues are not quite clear. First, the authors did not explain why they expected to identify such a phenomenon in Canada, a country with medium catheterization rates, when they did not mention any plateau effect in countries with higher catheterization rates.

Second, the authors suggest that the highest regional average catheterization rates for men $(638$ per 100000 population) and women (3I4 per Ioo ooo population) are lower than optimal catheterization rates. However, higher rates of catheterization have already been reached in several regions considered in this study for men and for women (Fig. 3 and Fig. 4 in the article), ${ }^{1}$ and there are reportedly no signs of a plateau effect. It is not clear why those higher values were not considered as the rates that are also lower than optimal catheterization rates, because that would be in accordance with the applied method of detecting an optimal rate of catheterization.

\section{Milorad Letic}

Department of Biophysics

University School of Medicine

Belgrade, Serbia

\section{REFERENCE}

I. Graham MM, Ghali WA, Faris PD, et al. Population rates of cardiac catheterization and yield of highrisk coronary disease. CMAJ 2005;173(I):35-9.

DOI:I0.1503/cmaj.I050183

\section{[The authors respond:]}

We thank Milorad Letic for his interest in our paper. We embarked upon this research because the concept of a plateau in detection of high-risk coronary disease is only theoretical, and no previous studies have determined whether a plateau actually exists. We chose to use regional catheterization rates from Alberta because of the availability of rich population-based data to perform this analysis. The highest regional average rates that were used in 